\title{
Microarray-based comparative genomic profiling of reference strains and selected Canadian field isolates of Actinobacillus pleuropneumoniae
} Julien Gouré ${ }^{1,5}$, Wendy A Findlay2 ${ }^{2}$, Vincent Deslandes ${ }^{1,5}$, Anne Bouevitch ${ }^{2}$, Simon J Foote ${ }^{2}$, Janet I MacInnes ${ }^{3}$, James W Coulton ${ }^{4,5}$, John HE Nash ${ }^{2,6}$ and Mario Jacques*1,5

\author{
Address: ${ }^{1}$ Groupe de Recherche sur les Maladies Infectieuses du Porc, Université de Montréal, St-Hyacinthe, Québec J2S 7C6, Canada, ${ }^{2}$ Institute \\ for Biological Sciences, National Research Council of Canada, Ottawa, Ontario K1A 0R6, Canada, ${ }^{3}$ Department of Pathobiology, Ontario \\ Veterinary College, University of Guelph, Guelph, Ontario N1G 2W1, Canada, ${ }^{4}$ Department of Microbiology and Immunology, McGill University, \\ Montréal, Québec H3A 2B4, Canada, ${ }^{5}$ Centre de Recherche en Infectiologie Porcine, Université de Montréal, St-Hyacinthe, Québec J2S 7C6, \\ Canada and ${ }^{6}$ Office of Biotechnology, Genomics and Population Health, Public Health Agency of Canada, Ottawa, Ontario K1A 0K9, Canada \\ Email: Julien Gouré - julien.goure@umontreal.ca; Wendy A Findlay - findlayw@gmail.com; \\ Vincent Deslandes - vincent.deslandes@umontreal.ca; Anne Bouevitch - Anne.Bouevitch@nrc-cnrc.gc.ca; Simon J Foote - Simon.Foote@nrc- \\ cnrc.gc.ca; Janet I MacInnes - macinnes@ovc.uoguelph.ca; James W Coulton - james.coulton@mcgill.ca; John HE Nash - john_nash@phac- \\ aspc.gc.ca; Mario Jacques* - mario.jacques@umontreal.ca \\ * Corresponding author
}

Published: 24 February 2009

BMC Genomics 2009, 10:88 doi:10.1/86/147|-2164-10-88
Received: 7 August 2008

Accepted: 24 February 2009

This article is available from: http://www.biomedcentral.com/147/-2/64/10/88

(C) 2009 Gouré et al; licensee BioMed Central Ltd.

This is an Open Access article distributed under the terms of the Creative Commons Attribution License (http://creativecommons.org/licenses/by/2.0), which permits unrestricted use, distribution, and reproduction in any medium, provided the original work is properly cited.

\begin{abstract}
Background: Actinobacillus pleuropneumoniae, the causative agent of porcine pleuropneumonia, is a highly contagious respiratory pathogen that causes severe losses to the swine industry worldwide. Current commercially-available vaccines are of limited value because they do not induce cross-serovar immunity and do not prevent development of the carrier state. Microarraybased comparative genomic hybridizations $(\mathrm{M}-\mathrm{CGH})$ were used to estimate whole genomic diversity of representative Actinobacillus pleuropneumoniae strains. Our goal was to identify conserved genes, especially those predicted to encode outer membrane proteins and lipoproteins because of their potential for the development of more effective vaccines.

Results: Using hierarchical clustering, our M-CGH results showed that the majority of the genes in the genome of the serovar $5 \mathrm{~A}$. pleuropneumoniae L20 strain were conserved in the reference strains of all I 5 serovars and in representative field isolates. Fifty-eight conserved genes predicted to encode for outer membrane proteins or lipoproteins were identified. As well, there were several clusters of diverged or absent genes including those associated with capsule biosynthesis, toxin production as well as genes typically associated with mobile elements.

Conclusion: Although A. pleuropneumoniae strains are essentially clonal, M-CGH analysis of the reference strains of the fifteen serovars and representative field isolates revealed several classes of genes that were divergent or absent. Not surprisingly, these included genes associated with capsule biosynthesis as the capsule is associated with sero-specificity. Several of the conserved genes were identified as candidates for vaccine development, and we conclude that $\mathrm{M}-\mathrm{CGH}$ is a valuable tool for reverse vaccinology.
\end{abstract}




\section{Background}

Actinobacillus pleuropneumoniae is a Gram-negative bacterium belonging to the family Pasteurellaceae. It is the etiological agent of porcine pleuropneumonia, a highly contagious respiratory infection that causes severe economic losses to the swine industry worldwide. The disease, transmitted by the aerosol route or direct contact with an infected pig, is characterized by hemorrhagic, fibrinous and necrotic lung lesions [1-3]. The clinical picture may range from peracute to chronic and asymptomatic carrier pigs can transmit the disease when introduced into uninfected herds. Two different biovars are recognised within the species: biovar 1 strains are nicotinamide adenine dinucleotide (NAD) dependent while biovar 2 strains are NAD-independent $[4,5]$. Based on capsular polysaccharides and lipopolysaccharide (LPS) Ochain components, 15 serovars have been described. Serovars 1 to 12 and 15 usually belong to biovar 1 ; whereas serovars 13 and 14 isolates are typically biovar 2 [5-8], however, biovar 2 variants of serovar 2, 4, 7 and 9 have been reported $[5,9,10]$.

Serotyping and other genetic typing methods for A. pleuropneumoniae have contributed greatly to surveillance and epidemiological studies. These tools provide important information for decision making in control programs aimed at eradication of virulent types of the bacterium. Nevertheless, serological cross-reactivity between $A$. pleuropneumoniae serovars 1,9 and 11 [11], between serovars 3,6 and 8 [12], and between 4 and 7 [13] has been described. In North America, serovars 1, 5 and 7 are reported to be the most prevalent, while serovars 2 and 9 are most commonly isolated in Europe, and serovar 15 is the predominant isolate from Australian pigs [14-16].

The virulence factors described for A. pleuropneumoniae include LPS, capsular polysaccharides, Apx toxins (I-IV), outer membrane proteins (OMPs) and various iron acquisition systems. However, the overall contribution of each component to the infection process remains unclear, as do the mechanisms of pathogenesis of this organism [1618]. All serovars are capable of causing disease; however, some serovars such as serovars 1, 2, 5a, 5b, 9 and 11 are more frequently involved in severe outbreaks with high mortality and pulmonary lesions. Several reports have suggested that the differences in virulence among the serovars can mainly be attributed to different combinations of Apx toxins and the amount of capsular polysaccharides $[17,19-21]$. Almost all of the currently available vaccines against $A$. pleuropneumoniae are either inactivated wholecell bacterins or subunit combinations of Apx toxins and proteins or OMPs [22]. Experimental challenge and field usage data indicate that these vaccines neither induce cross-serovar immunity nor prevent development of the carrier state and have little impact on morbidity [23-26].
Molecular techniques, including Multilocus Enzyme Electrophoresis (MLEE) [27,28], Pulsed-Field Gel Electrophoresis (PFGE) [29] and Amplified Fragment Length Polymorphism (AFLP) analysis [30] have been used to study different strains of $A$. pleuropneumoniae. These investigations have shown that genetic diversity among isolates of the same serovar may be almost equivalent to that in the species as a whole, suggesting that A. pleuropneumoniae strains are genetically very similar and would seem to have a clonal population structure. However, restriction analysis fingerprinting [31,32] studies revealed that with the exception of serovars 1 and 9, the reference strains of $A$. pleuropneumoniae are clearly different. Similarly, work of Chevallier et al. and Møller et al. revealed a more pronounced heterogeneity in the chromosomal structure among strains of serovars $1,5 a, 5 b, 7,8$ and 12 [27,29]. The notion of heterogeneity amongst serovars is also supported by early free-solution DNA-DNA hybridization studies that showed that representative strains of 12 serovars of A. pleuropneumoniae shared 74 to $90 \%$ sequence homology with A. pleuropneumoniae serovar 1 [32].

We are using a reverse vaccinology approach to identify new candidates for the development of cross-protective vaccines against $A$. pleuropneumoniae. Using the complete and annotated A. pleuropneumoniae L20 genome [33], Chung and coworkers published a list of 93 predicted OMPs or lipoproteins of A. pleuropneumoniae obtained by using five genome scanning programs [34]. The availability of the genome sequence of A. pleuropneumoniae also enables us to study diversity of A. pleuropneumoniae on a genome-wide scale. To date, two additional complete genomic sequences have become available, A. pleuropneumoniae serovar 3 JL03 [GenBank:CP000687] [35], and A. pleuropneumoniae serovar 7 AP76 [GenBank:CP001091].

$\mathrm{M}-\mathrm{CGH}$ is a powerful tool to estimate whole genomic diversity and to study the gene content and locate genomic islands in closely related strains of bacteria [3642]. In the present study, this method was applied for the first time to study genetic relationships among reference strains of the 15 serovars of A. pleuropneumoniae and representative field isolates. Our goal was to identify conserved genes with particular emphasis on those predicted to encode outer membrane proteins and lipoproteins because of their potential for the development of improved vaccines.

\section{Results and Discussion}

The first microarray-based study of A. pleupneumoniae, which used a full-genome microarray based upon a draft version of the genome sequence of strain L20, evaluated the effects of iron limitation [43]. From the recently completed genome sequence of A. pleuropneumoniae L20 [33], a full genome A. pleuropneumoniae microarray (AppChip2; 
GEO Accession Number GPL6658), which takes into account corrections from the draft sequence and comprises reporters matching the sequence of more than 1800 genes, was developed and used in this study. With microarray hybridization, the presence of a specific gene in a test strain is based on comparison of the intensity of the hybridization signal obtained with the genomic DNA of the tester strain to that obtained with the genomic DNA of the control strain for the corresponding reporter. The ratio of intensity of tester signal to control signal is usually expressed on a $\log 2$ scale and we used a threshold of -1 to define genes likely to be divergent in sequence from the strain L20 genome. We have shown previously that genes absent from the tested strain usually have log2 ratio values less than -3 [37]. The overall genomic variability of the 15 A. pleuropneumoniae serovars is shown in Figure 1 where the number of serovars in which a gene is variable is plotted for each gene with the gene order corresponding to the strain L20 genome sequence. Although most genes are conserved across the 15 serovars, we observed a number of distinct clusters of absent/divergent genes. A total of 205 genes were identified as either divergent or highly divergent/absent in the 15 reference strains tested (additional file 1). In the largest cluster (APL_0488 to
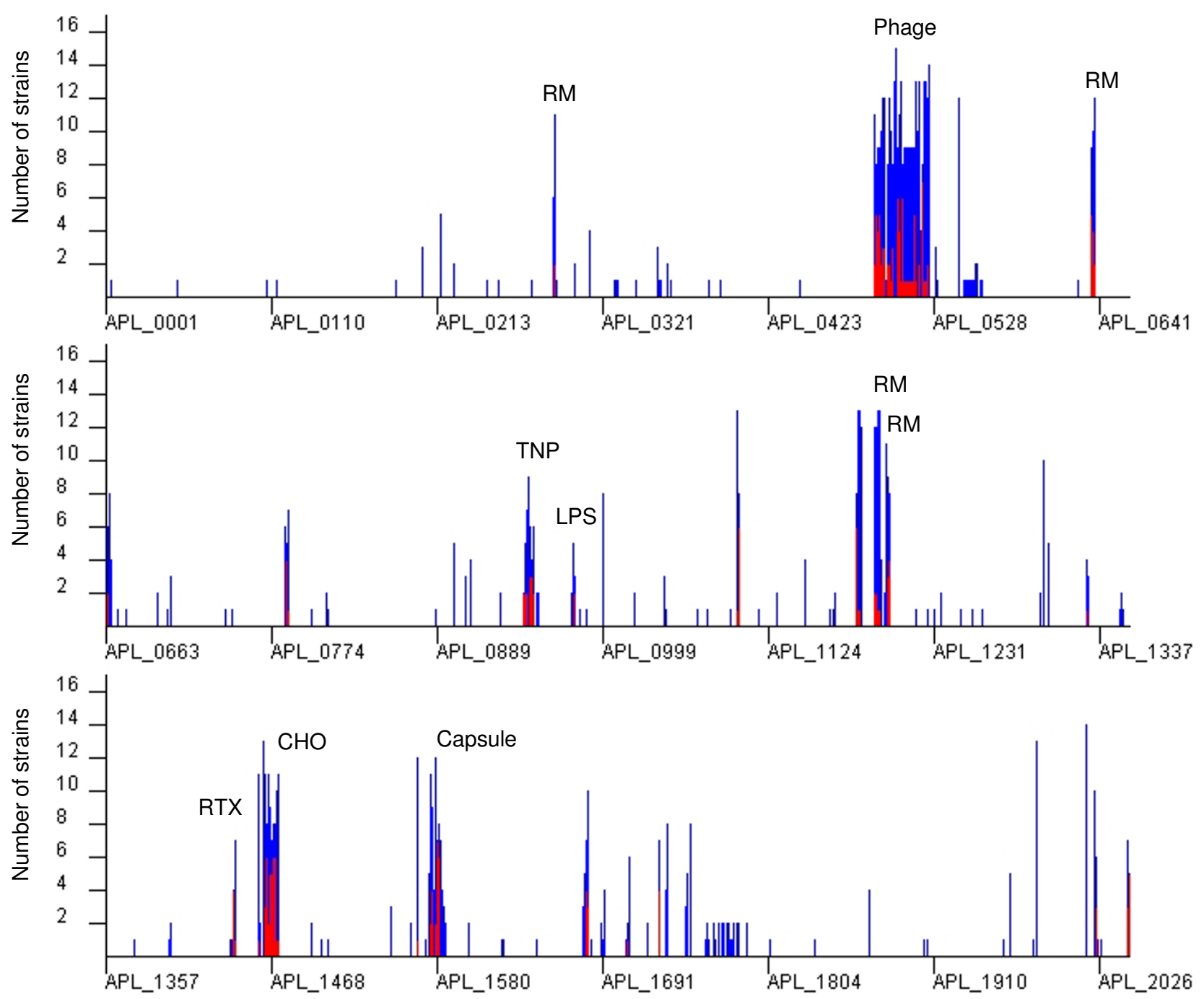

Figure I

Number of reference strains representing the I 5 serovars of $A$. pleuropneumoniae where gene is divergent or missing for each gene, ordered as in A. pleuropneumoniae L20 genome sequence and based on $M$-CGH results. (Blue: -3<Log2Ratio<-I, Red: Log2Ratio<-3). RM, DNA restriction/modification enzymes; TNP, transposon; LPS, lipopolysaccharide biosynthesis genes; RTX, toxin genes; $\mathrm{CHO}$, carbohydrate biosynthesis genes. 
APL_0525), many genes are annotated as potential phage or prophage genes, suggesting that this cluster might correspond to a phage. A smaller cluster around APL_0947 to APL_0952 corresponds to genes annotated as transposonrelated. Several of the other clusters correspond to genes annotated as components of DNA restriction and modification systems. Clusters of variable genes involved in toxin production, and in capsule and LPS biosythesis were observed as expected. Several other clusters containing unannotated genes may warrant further investigation. Experiments with closely related bacterium Actinobacillus suis showed only weak hybridization to the AppChip2 microarray, suggesting that the nucleotide sequence identities for the ORFs are low; consistent with earlier DNADNA hybridization studies [32] (data not shown).

We used hierarchical clustering based on the M-CGH results to examine the relationship between A. pleuropneumoniae serovars based on genomic content. The dendrogram of the data excluding phage and transposon-related genes is shown in Figure 2. This tree has very similar structure to the tree based on data from all 1857 genes on AppChip2 (data not shown), and both show serovars 5a and $5 \mathrm{~b}$ forming a distinct subclade. Also, the antigenically related serovars 1,11 , and 9 cluster together as do crossreactive serovars 4 and 7 . Nevertheless we do not observe clustering of serovars 1,5 and 7 which are the most common ones found in North America or of serovars 13 and 14 which represent biovar 2 .

The M-CGH patterns for capsule biosynthesis genes (Figure $3 \mathrm{~A}$ ) show a high degree of variability for the various serovars compared to serovar $5 \mathrm{~b}$. This is to be expected as

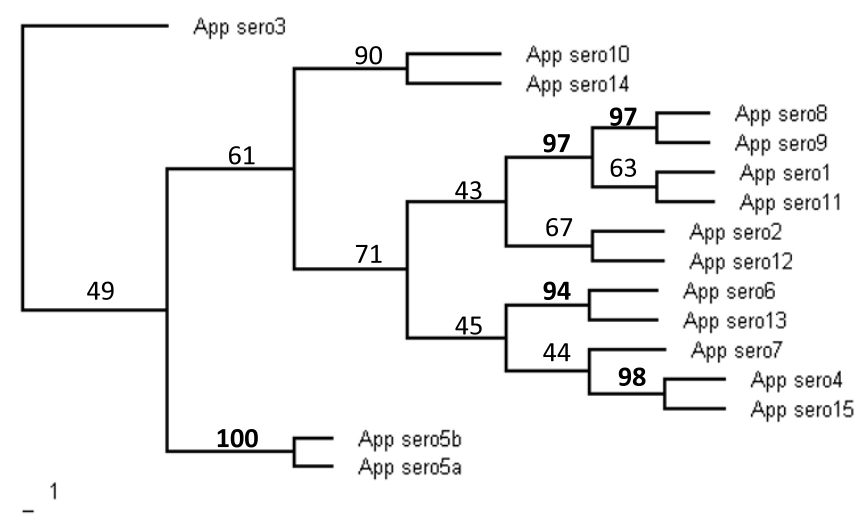

Figure 2

Hierarchical clustering of $A$. pleuropneumoniae reference strains based on $\mathrm{M}-\mathrm{CGH}$ data excluding phage and transposase genes. The dendrogram was produced using the MEV software from the J. Craig Venter Institute with Euclidean distance and average linkage clustering $(\mathrm{n}=$ 1000 bootstrap iterations). the capsule is a major determinant of the A. pleuropneumoniae serovar $[6,44]$. Much less variation across serovars is observed with the $c p x$ genes which are involved in capsule export than with the cps and $k d s$ genes which are involved in capsule biosynthesis.

Serotyping of A. pleuropneumoniae is based mainly on the capsular polysaccharide (CPS) and the lipopolysaccharide antigenic O-chain component [44]. The M-CGH patterns for capsule biosynthesis genes (Figure 3A) show a high degree of variability for the various serovars compared to serovar 5b, except for serovar 5a. The structures of CPS from subtypes $5 \mathrm{a}$ and $5 \mathrm{~b}$ have been determined $[45,46]$. Both structures share a common backbone consisting of disaccharide repeating units, $[\rightarrow 6)-\alpha-D-G c_{p} N A c(1 \rightarrow 5)$ $\beta-\mathrm{KDO}_{\mathrm{p}}-(2 \rightarrow]_{\mathrm{n}}$. In addition, the CPS of serovar $5 \mathrm{~b}$ has a lateral $\beta$-D-glucopyranosyl residue [45]. Moreover, both subtypes contain LPS 0-chain components with the same basic polysaccharide structure of a linear unbranched homopolymer of 1,6-linked $\beta$-D-galactopyranosyl residues [47]. Thus, the related structures of the capsular polysaccharides of subtypes $5 \mathrm{a}$ and $5 \mathrm{~b}$ are consistant with the identical M-CGH patterns for capsule biosynthesis genes for these two serovars.

The M-CGH pattern of toxin biosynthesis genes for the reference strains of the 15 serovars is shown in Figure 3B. The pattern observed for the toxin genes is in agreement with the results of Frey and co-workers [48] who reported that the apxIDB genes are missing in serovar 3; apxIAC are missing in serovars 2, 3, 4, 6, 7, 12, 13 and 15; apxIIAB genes are missing in serovars 10 and 14 . Consistent with previous reports [49-51], apxIVA was present in all serovars; as apxIII genes are not present in A. pleuropneumoniae serovar 5 strains (including L20) they were therefore not included on the AppChip2 microarray.

The genomic variability of 15 representative field isolates of A. pleuropneumoniae serovars 1,7 and 15 is shown in Figure 4 . For each serovar, the number of strains in which a gene is variable is plotted for each gene with the gene order corresponding to the strain L20 genome sequence. For serovars $5 \mathrm{a}$, we observed only one cluster of highly variable genes which is the largest cluster (APL_0488 to APL_0525) containing many genes annotated as potential phage or prophage genes in serovar $5 \mathrm{~b}$.

To evaluate relationships among the 21 field isolates of serovars 1, 5, 7 and 15 and their respective reference strains, we performed hierarchical clustering to build dendrograms based upon analysis of the data excluding phage and transposase genes (Figure 5). Except for serovar 7, strains from the same serovar formed a cluster. The analysis indicated that the Ontario serovar 7 field isolates 881 and 1951 clustered separately from the Quebec and Sas- 
A Capsule biosynthesis genes

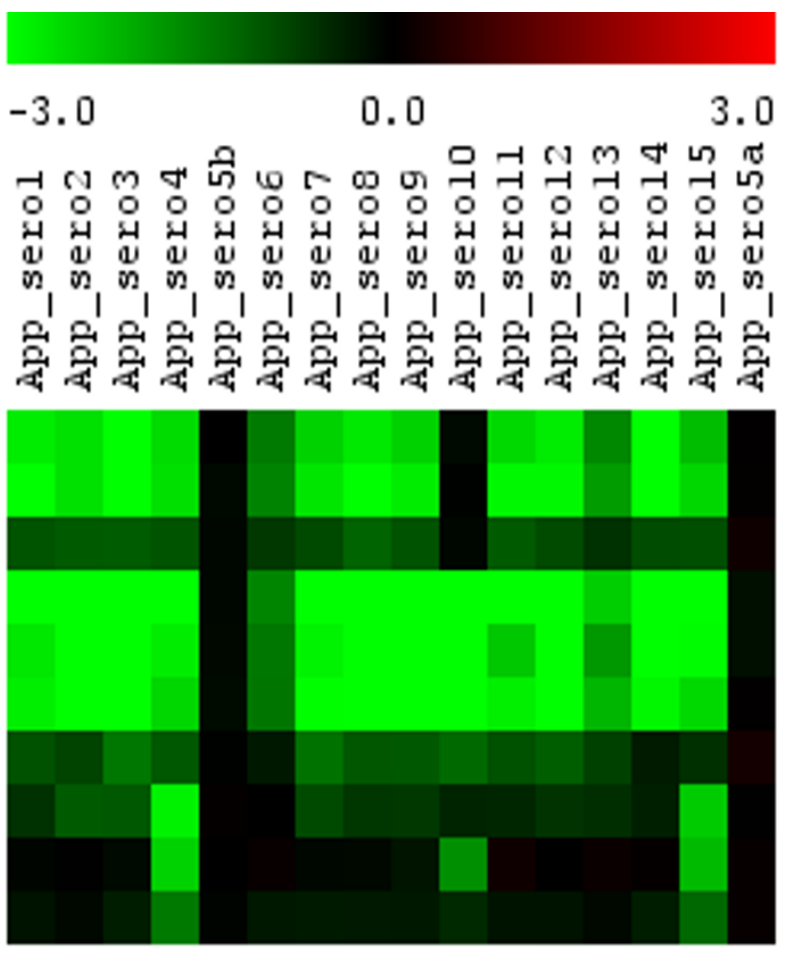

B Toxin genes
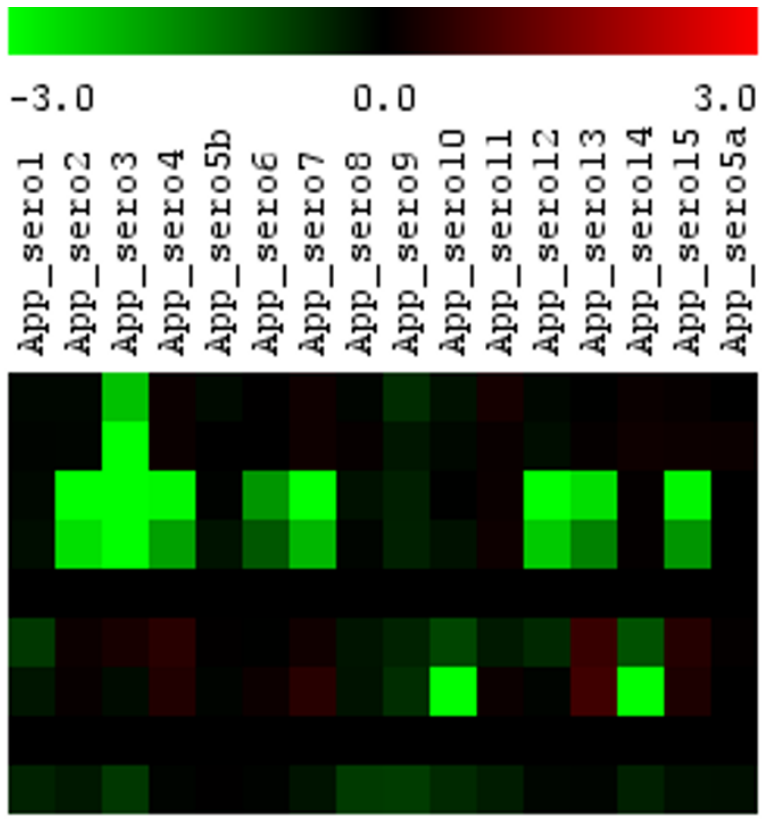

APL $1576 ; \mathbf{k p s F}$

APL $^{-1577 ; \mathbf{k d s B}}$

APL ${ }^{-1578 ; k d s A}$

APL $^{-} 1579 ; \operatorname{cps} 5 \mathrm{C}$

APL $^{-} 1580$; Cps 5B

APL $^{-1581 ; A P L ~} 1581 /$ cps5A

$\mathrm{APL}^{-} 1582 ; \mathrm{cpx} \overline{\mathrm{D}}$

APL $^{-} 1583$; cpxC

APL ${ }^{-1584 ; ~ c p x B}$

APL ${ }^{-} 1585$; CPXA
APL 1442; apxID

APL $^{-1443 ; \text { apxIB }}$

APL $^{-1444}$; apxIA

APL $^{-1445}$; apxIC

APL 0955 ; apxIIB

APL ${ }^{-} 0956$; apxIIA

APL 0998 ; apxIVA

Figure 3

Variability of genes involved in toxin and capsule biosynthesis across the $A$. pleuropneumoniae reference strains representing the $\mathbf{I} 5$ serovars. Green indicates that the gene is divergent in sequence or absent in the tester strain. 

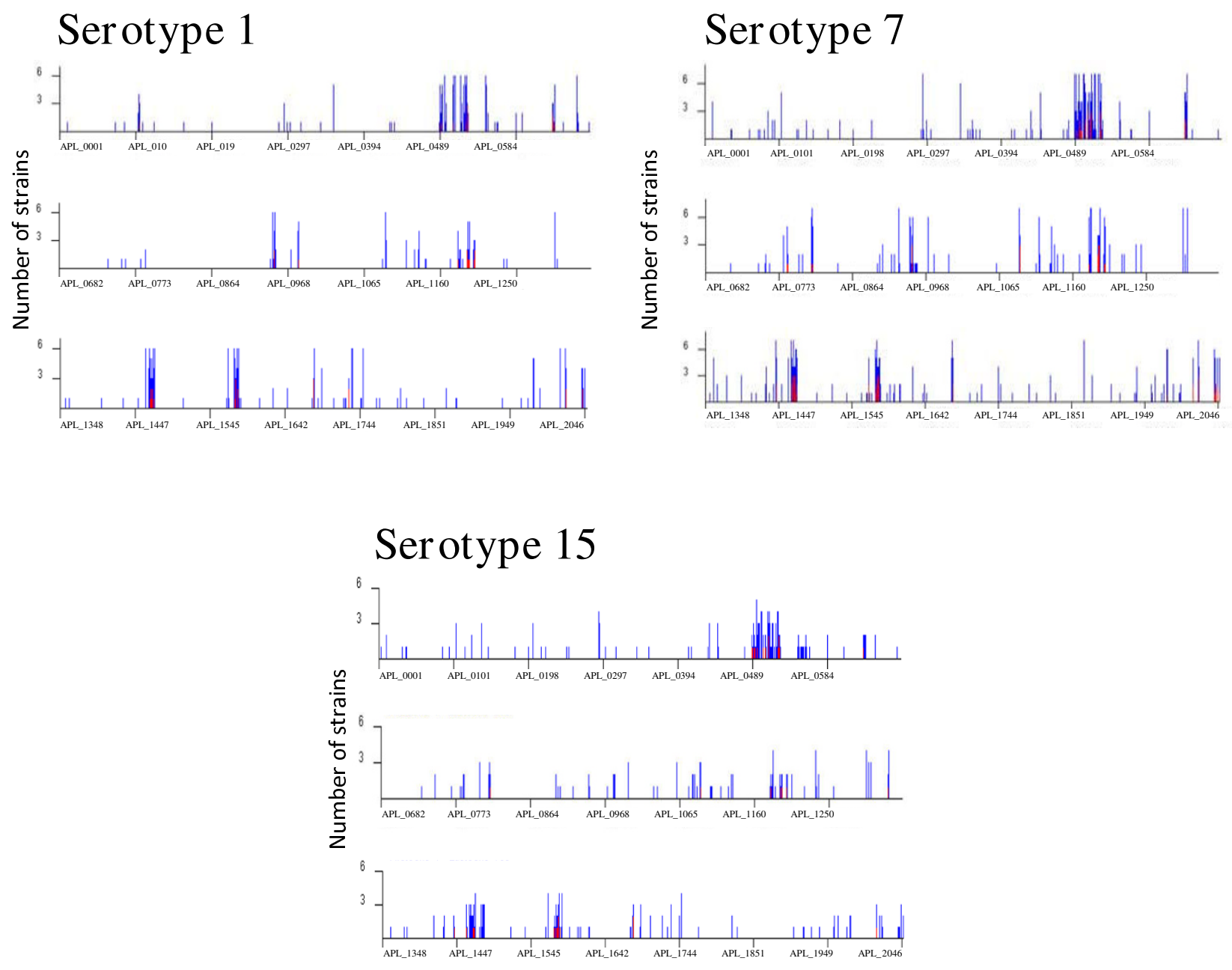

\section{Figure 4}

Number of strains from I 5 fresh field isolates of $A$. pleuropneumoniae serovars I, 7 and 15 where the sequence is divergent or absent for each gene, ordered as in A. pleuropneumoniae L20 genome sequence and based on MCGH results.

katchewan serovar 7 strains. In contrast, Ontario and Saskatchewan serovar 1 field isolates were genetically very similar. As expected, the eight serovar $5 \mathrm{a}$ and $5 \mathrm{~b}$ strains form a distinct cluster. These results are consistent with earlier restriction endonuclease fingerprinting analysis, which revealed limited heterogeneity amongst isolates of serovar 1 or serovar 5 whereas serovar 7 isolates showed greater variation [31].

In Canada, the most prevalent serovars are 1, 5 and 7. However, other serovars have also been isolated from sporadic outbreaks of pleuropneumonia. This is the first report describing the isolation and characterization of serovar 15 strains from field cases of porcine pleuropneu- monia in North America. In previous reports, serovar 15 strains have only been isolated from pigs in Australia and Japan $[15,52]$. Hierarchical clustering based on our MCGH results showed that the three serovar 15 field strains (05-13146, 05-14657, 05-20080) are closely related to the reference strain of serovar 15 of $A$. pleuropneumoniae. These three serovar 15 field strains also had the same MCGH pattern of toxin biosynthesis genes as reported for serovar 15 field strain isolated in Japan [52] and the reference strain (HS143). In these strains the Apx structural genes, apxIIA, apxIIB and apxIVA, but not apxIA and $a p x I C$, and Apx secretion genes apxIBD were detected (data not shown). 


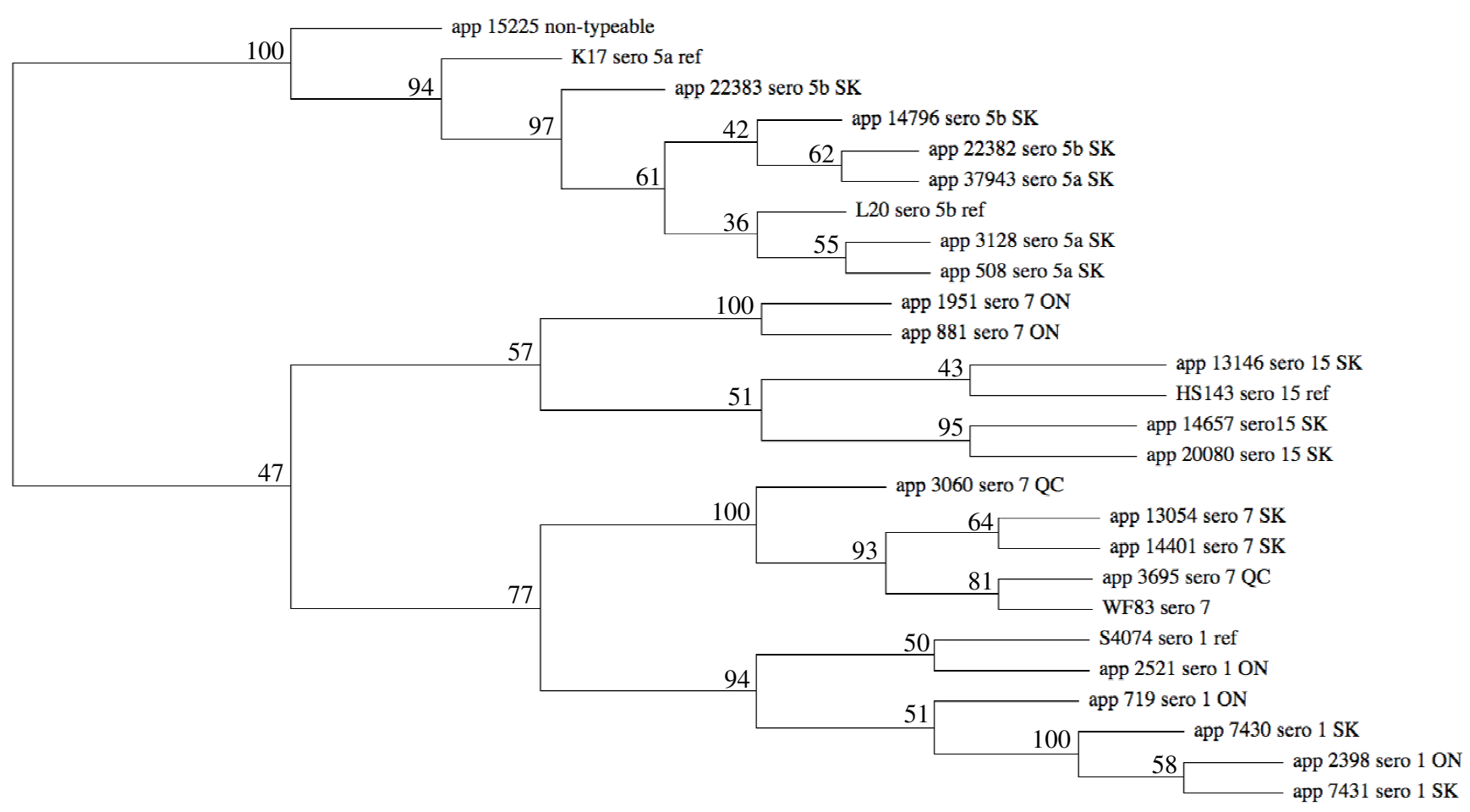

\section{Figure 5 \\ Hierarchical clustering of field isolates of $A$. pleuropneumoniae based on $\mathrm{M}-\mathrm{CGH}$ data excluding phage and transposase genes.}

The serologically non-typeable isolate, 05-15225, possessed the same M-CGH pattern of toxin biosynthesis genes as the reference strains of serovars $5 \mathrm{a}$ and $5 \mathrm{~b}$. The $\mathrm{M}$ CGH pattern for capsule biosynthesis genes of the 0515225 isolate showed little variability compared to serovar 5b. Only two genes involved in capsule biosynthesis, cps $C$ and $c p s D$ had a $\log 2$ ratio value less than -1 . These two genes may be deleted or diverged in sequence in this isolate, which could explain why it was not typable by serology. Nevertheless, the dendrogram showed that 0515225 isolate is closely related to the serovar 5 (subtypes $\mathrm{a}$ and b), suggesting that it can be classified in serovar 5 strains.

Other clustering methods or distances were applied to the data set in order to verify that the clusters we identified were robust (data not shown). Hierarchical clustering with Manhattan Distance metrics and K-Medians Clustering (K-MC) [53] yielded highly similar results: strains from the same serovar clustered together, with the serovar 7 strains from Ontario grouped with serovar 15 strains, although the serotype 1513146 strain was left on its own following K-Medians Clustering. In both cases, the nontypeable 05-15225 isolate clustered with serovar 5 strains. Cluster Affinity Search Technique [54] generated the same results, however serovar 15 strains were scattered in three different clusters, and were not grouped with serovar 7 strains from Ontario.

Commercially available vaccines against $A$. pleuropneumoniae, including inactivated whole-cell bacterins and subunit vaccines, have limited efficacy and little impact on morbidity. Moreover, these vaccines confer only partial protection against the homologous serovar and generally do not confer protection against challenge with heterologous serovars [55-57]. A major focus of research for the development of new vaccines against porcine pleuropneumonia has been to identify proteins that are conserved in all 15 serovars of A. pleuropneumoniae and that generate cross-protection against strains of all serovars. Based on the principle that surface-exposed antigens are more susceptible to recognition by antibodies and therefore are the most suitable candidates for a vaccine, the full genome of A. pleuropneumoniae L20 was screened using bioinformatics predictor programs to identify open reading frames encoding putative proteins localized at the bacterial outer membrane and 45 OMPs and 48 lipoproteins were predicted [34]. Using M-CGH to identify genes that are highly conserved among the reference strains of the 15 serovars of A. pleuropneumoniae, as well as among field isolates, we identified 58 potential vaccine targets (24 OMPs and 34 lipoproteins) (Table 1) that are conserved among 
all serovars and biovars. Among these candidates, four have been shown to be expressed in vivo. Using selective capture of transcribed sequences analysis (SCOTS) [58], it has been shown that ompA (APL_1421) and APL_0829 are expressed by $A$. pleuropneumoniae in necrotic pig lung tissue. Furthermore, polyamine transport protein D (APL_0368), Omp P2 (APL_0649), OmpA (APL_1421) and outer membrane antigenic lipoprotein B (APL_1930) are required for efficient colonization of the porcine host by $A$. pleuropneumoniae as shown by signature-tagged mutagenesis (STM) experiments $[59,60]$.

A. pleuropneumoniae bind preferentially to cells of the lower respiratory tract, where some essential nutrients for the growth of bacteria, such as iron, are limited. A. pleuropneumoniae has developed several iron uptake systems including the hydroxamate siderophore receptor FhuA (APL_2016), a hemoglobin-binding receptor HgbA (APL_1047) and a transferrin receptor complex composed of two outer membrane proteins, transferrin-binding protein A (TbpA; APL_1567) and transferring-binding protein B (TbpB; APL_1568). Not only is iron essential for growth of bacteria but iron-restriction is an important sig- nal that controls expression of many genes including some coding for virulence factors [43]. Hence, these proteins involved in iron uptake are considered as candidates for development of subunit vaccines. However, our MCGH results showed that only one protein involved in iron uptake, TbpA, is conserved among the 15 serovars of A. pleuropneumoniae. This observation could explain the partial protection against infection with heterologous strains conferred by an acellular pentavalent subunit vaccine containing the TbpB of A. pleuropneumoniae serovar 7 [26].

The NADPH-sulfite reductase hemoprotein CysI (APL_1842) of A. pleuropneumoniae, a cytoplasmic protein involved in cellular metabolism, has also been shown to induce protective immunity against a homologous challenge [61]. Our CGH analysis showed that CysI is conserved among all strains tested in this study, thus this protein could represent an interesting vaccine target.

Two genes (APL_1421 and APL_1852), encoding homologs of outer membrane protein A (or OMP P5), were identified as potential vaccine targets in this study.

Table I: A. pleuropneumoniae reference strains and field isolates analyzed by M-CGH in this study.

\begin{tabular}{lll}
\hline Strains & Serovars & Source \\
\hline Reference strains & & All from K.R. Mittal' \\
S4074 & 1 & \\
S1536 & 2 \\
SI42I & 3 \\
M62 & 4 \\
KI7 & $5 a$ \\
L20 & $5 b$ \\
Femø & 6 \\
WF83 & 7 \\
405 & 8 \\
CV I326I & 9 \\
I3069 & 10 \\
56153 & 11 \\
8329 & 12 \\
N273 & 13 \\
3906 & 14 \\
HSI43 & 15
\end{tabular}

Field strains

05-7430, 05-743।

$719,2398,2521$

04-37943, 04-3128, 05-508

04-14796, 03-22382, 03-22383

05-3695, 06-3060

04-13054, 05-1440|

881,1951

05-13|46, 05-14657, 05-20080

$05-15225$

$\begin{array}{ll}\text { I } & \text { M. Ngeleka } 2 \\ 1 & \text { D. Slavic }{ }^{3} \\ 5 \mathrm{a} & \text { M. Ngeleka 2 } \\ 5 \mathrm{~b} & \text { M. Ngeleka 2 } \\ 7 & \text { S. Messier } \\ 7 & \text { M. Ngeleka } 2 \\ 7 & \text { D. Slavic } \\ \text { 15 } & \text { M. Ngeleka 2 } \\ \text { non-typeable } & \text { M. Ngeleka 2 }\end{array}$

I Faculté de médecine vétérinaire, Université de Montréal, St-Hyacinthe, QC

2 Prairie Diagnostic Services, University of Saskatchewan, Saskatoon, SK

3 Ontario Veterinary College, University of Guelph, Guelph, ON 
APL_1421 and APL_1852 have $70.6 \%$ identity and showed $75.6 \%$ and $70.6 \%$ identity, respectively, to OmpA from the bovine pathogen Mannheimia haemolytica, which has surface exposed epitopes and is recognized by convalescent bovine sera $[62,63]$. In addition to ompA (APL_1421), the outer-membrane lipoprotein LolB (APL_0777), is expressed in vivo by A. pleuropneumoniae and they have been identified and characterized as potential components of a cross-protective sub-unit vaccine against A. pleuropneumoniae [64]. However, Oldfield et al. reported that neither of these proteins was capable of eliciting protective immunity against A. pleuropneumoniae challenge [64]. The outer membrane protein PalA (APL_0304) was also on our list of conserved proteins. Nevertheless, it has been shown that vaccination with PalA increases the severity of A. pleuropneumoniae infection in vaccinated pigs [65]. Thus, the deleterious effect of PalA in vaccination and the inability of LolB and OmpA to induce protective immunity eliminate these proteins from the list of potential vaccine candidates.

Interestingly, homologs of some of the remaining conserved vaccine candidates are already under investigation as vaccine components in other bacteria (including other Pasteurellaceae). For example, the lipoprotein Plp4 from $M$. haemolytica, which had $85.3 \%$ identity with lipoprotein PlpD (APL_0460), was identified by screening antigens of $M$. haemolytica with sera from Presponse ${ }^{\text {TM }}$ vaccinated calves (a cell-free culture supernatant $M$. haemolytica A1 vaccine) that were protected from $M$. haemolytica A1 infections [66], thus suggesting PlpD may be a protective antigen. Another candidate, APL_0378, a glycerophosphodiester phosphodiesterase (GlpQ), showed $82 \%$ and $79.5 \%$ identity to GlpQ of Pasteurella multocida and protein D of Haemophilus influenzae, respectively. The role of GlpQ in A. pleuropneumoniae and P. multocida is unknown, however, its homolog in H. influenzae has been shown to mediate the acquisition of choline directly from the membranes of epithelial cells in culture and incorporate it into its own LPS [67]. H. influenzae protein $\mathrm{D}$ has been showed to elicit cross-protection against virulent heterologous strains of $H$. influenzae in rats [68]. In contrast to $H$. influenzae, GlpQ in P. multocida is not surface-exposed and is unable to stimulate protective immunity, even though vaccinated animals have high antibody titers [69]. Therefore, the location of GlpQ and accessibility of GlpQ-specific antibodies should be determined in A. pleuropneumoniae.

OMP P4 (ompP4; ALP_0389) is another attractive surface exposed antigen [70] showing 65\% identity to lipoprotein $\mathrm{E}$ (also known as OMP P4) in $H$. influenzae, which is highly conserved among both typeable and nontypeable strains [71]. In nontypeable strains of $H$. influenzae (NTHi), OMP P4 is essential for utilization of NAD and subsequent growth $[72,73]$. Intranasal immunization of mice with OMP P4 in a mucosal adjuvant induces protective immune responses against NTHi infections and notably, a mucosal immune response, which reduces NTHi nasopharynx colonization [74]. These observations in $H$. influenzae suggest that lipoprotein E (APL_0389) may be an attractive candidate for a vaccine against A. pleuropneumoniae.

PCP (peptidoglycan-associated lipoprotein cross-reacting protein) of $H$. influenzae is under investigation since it is surface-exposed and anti-PCP serum shows bactericidal activity against several clinical isolates of type $\mathrm{b}$ and nontypeable $H$. influenzae [75]. Outer membrane lipoprotein SlyB (APL_0037) shows highest identity $(71.4 \%)$ to this protein. However, although PCP from P. multocida (also surface-exposed) is recognized by convalescent chicken antiserum, it is unable to stimulate protective immunity [69].

The polyamine transport protein D, PotD (APL_0368), has extensive homology to a $38 \mathrm{kDa}$ lipoprotein, Lpp38 of $M$. haemolytica. Lpp38 is surface-exposed and is recognized by sera from calves resistant to infection after natural exposure to $M$. haemolytica and by sera from calves vaccinated with $\mathrm{M}$. haemolytica $\mathrm{A} 1$ outer membranes or with live bacteria [76]. Recently, in the human pathogen Streptococcus pneumoniae, PotD has been reported to be involved in virulence in both an animal model of sepsis and pneumonia $[77,78]$. Active immunization of mice with recombinant PotD induces a vigorous antibody response and provides a significant degree of protection against lethal pneumococcal infection [79]. These data suggest that PotD plays a role in the development of immunity to bacterial infections and may be a protective antigen.

Homologs of the outer membrane protein D15 (APL_0411) have been reported in several pathogenic bacteria including $H$. influenzae, Haemophilus ducreyi, $P$. multocida, Neisseria meningitidis and Shigella dysenteriae [80-83]. These studies suggest a role for these proteins in pathogenesis and immunity. Notably, it has been shown that D15 confers protection against homologous and heterologous strains of $H$. influenzae in animal models [8486]. Similarly, Oma87, a closely related homolog in $P$. multocida, has been shown to elicit protection in animal model of infection [83]. Thus D15 is potentially an attractive vaccine target.

\section{Conclusion}

In this study, we have shown that M-CGH can be a useful tool to identify candidates for reverse vaccinology in order to develop subunit vaccines to A. pleuropneumoniae. After comparing CGH data for 15 reference strains and 21 fresh 
field isolates, we have identified 58 conserved genes that are predicted to code for outer membrane proteins or lipoproteins. This could assist in development of vaccines with efficacy across serovar boundaries. Future investigations will include the use of microarray transcript profiling experiments of $A$. pleuropneumoniae isolated from infected pigs to identify potential vaccine candidates that are both conserved and expressed in vivo during infection in pigs.

\section{Methods \\ Bacterial strains}

Reference strains and field isolates of A. pleuropneumoniae used in this study are listed in Table 2. All A. pleuropneumoniae strains were inoculated into Brain-Heart Infusion (BHI, Difco Laboratories, Detroit, MI) medium supplemented with NAD: either $15 \mu \mathrm{g} / \mathrm{ml}$ in agar or $5 \mu \mathrm{g} / \mathrm{ml}$ in broth. Cultures were grown at $37^{\circ} \mathrm{C}$ for $16-18$ hours before genomic DNA isolation.

\section{Construction of an A. pleuropneumoniae amplicon-based DNA microarray (AppChip 2)}

PCR primers were designed for 1954 genes of the A. pleuropneumoniae L20 (serovar 5b) genome using the Primer3 program [87] controlled by an automated script as described previously [make_primers code available at http://www.ibs-isb.nrc-cnrc.gc.ca/glycobiology/

group software e.html] [88]. Most sequences of length greater than $2000 \mathrm{nt}$ were split to create two or more reporters corresponding to a single large ORF. Primer selection parameters were standardized and included similar predicted melting temperature $\left(60 \pm 2{ }^{\circ} \mathrm{C}\right)$, uniform length (25 nt), and minimum amplicon size of $160 \mathrm{bp}$. Generation of PCR amplicons and fabrication of DNA microarrays were described previously [88]. Details on the construction of this microarray (AppChip2) are available at NCBI (GEO Accession Number GPL6658). The AppChip2 microarray comprises validated amplicons covering $>92 \%$ of the ORFs longer than 160 bp in the final A. pleuropneumoniae L20 genome sequence (GenBank accession number $\underline{\mathrm{CP000569}}$ ).

\section{Isolation of genomic DNA}

A. pleuropneumoniae strains were harvested after growth on agar plates for 16-18 h, resuspended in $\mathrm{H}_{2} \mathrm{O}$, and treated with lysozyme (Roche, Laval, QC) and RNase A (Qiagen, Mississauga, ON) for $10 \mathrm{~min}$ at room temperature. The cell suspensions were then digested with proteinase $\mathrm{K}$ (MBI Fermentas, Burlington, ON) for $1 \mathrm{~h}$ at $37^{\circ} \mathrm{C}$, and complete lysis was obtained by addition of sodium dodecyl sulfate to a final concentration of $0.1 \%$ (wt/vol). Genomic DNA, extracted from the cell lysates by two extractions with phenol-chloroform-isoamyl alcohol (25:24:1) and two extractions with chloroform, was precipitated in ethanol.

\section{Genomic DNA labelling}

Isolated genomic DNA was fragmented by nebulization. One hundred $\mu$ g of DNA in $\mathrm{H}_{2} \mathrm{O}$ and $35 \%$ glycerol (v/v) was placed in an AeroMist Nebulizer chamber (IPI Medical Products, Chicago, IL), and sheared by passing nitrogen gas through the chamber at 15 psi for $1 \mathrm{~min}$. The DNA was precipitated with ethanol and suspended in $100 \mu \mathrm{l}$ of $\mathrm{ddH} 2 \mathrm{O}$. Typically, the DNA was fragmented to a range of 0.4 to $12 \mathrm{~kb}$ in size. Five $\mu \mathrm{g}$ of fragmented DNA were fluorescently labeled using direct chemical coupling with the Label-IT (Mirus Corp., Madison, WI) cyanine dyes Cy3 and $\mathrm{Cy} 5$ as recommended by the manufacturer. Probes were purified from unincorporated dyes by passing samples through Qiaquick columns (Qiagen, Mississauga, ON). Labeled DNA sample yields and dye incorporation efficiencies were assessed using a Nanodrop ND-1000 spectrophotometer (Nanodrop, Rockland, DE).

\section{Microarray hybridizations}

The hybridization profile for each strain was obtained by co-hybridizing labeled DNA from the tester strain with labeled DNA from the A. pleuropneumoniae serovar $5 \mathrm{~b}$ (L20) control strain to the microarray. DNA from tester strains was labeled with Cy3 and DNA from the control strain with Cy5. Dye swaps were performed on selected strains to test for any dye-incorporation bias. Labeled samples were normalized by selecting tester/control sample pairs with similar dye incorporation efficiencies. Equivalent amounts $(2 \mu \mathrm{g})$ of labeled tester and control samples were pooled, lyophilized, and then re-suspended in $42 \mu \mathrm{l}$ of hybridization buffer [ $1 \times$ DIGEasy hybridization solution (Roche Applied Science); $0.5 \mu \mathrm{g} / \mu \mathrm{l}$ of Torulla yeast tRNA (Invitrogen); $0.5 \mu \mathrm{g} / \mu \mathrm{l}$ of salmon sperm genomic DNA (Invitrogen)]. Labeled gDNA was denatured at $65^{\circ} \mathrm{C}$ for $5 \mathrm{~min}$ and applied to the microarray. Hybridizations were performed overnight at $37^{\circ} \mathrm{C}$ under $22 \times 40$-mm glass cover slips in a high-humidity chamber. Microarrays were washed $2 \times 5 \mathrm{~min}$ at $50^{\circ} \mathrm{C}$ in $1 \times \mathrm{SSC}$ with $0.1 \%$ SDS, then $2 \times 5 \mathrm{~min}$ at $50^{\circ} \mathrm{C}$ in $0.5 \times$ SSC, and $1 \times 5 \mathrm{~min}$ at $50^{\circ} \mathrm{C}$ in $0.1 \times$ SSC. Slides were spun dry $(500$ $\times \mathrm{g}, 5 \mathrm{~min}$ ) and stored in lightproof containers until scanned.

\section{Data acquisition and analysis}

After hybridization with labeled gDNA, microarray slides of the 15 reference serovars were scanned using a Chipreader laser scanner (BioRad, Mississauga, ON) according to the manufacturer's recommendations. Spot quantification, signal normalization and data visualization were performed using ArrayPro Analyzer v4.5 (Media Cybernetics, Silver Spring, MD). Net signal intensities were obtained by performing local-ring background subtraction. "Tester signal" is defined as the signal intensity of the selected A. pleuropneumoniae reference strains labeled with appropriate fluorescent dye, while "control signal" is 
Table 2: In silico predicted OM proteins and lipoproteins from A. pleuropneumoniae (according to Chung et al. 2007), which are conserved amongst the 15 reference strains and the $2 I$ field isolates tested by M-CGH in this study.

\begin{tabular}{|c|c|c|}
\hline OrfID & Gene & Product \\
\hline \multicolumn{3}{|c|}{ Predicted outer membrane proteins } \\
\hline APL_0006 & ompP2A & outer membrane protein $\mathrm{P} 2$ \\
\hline APL_0049 & APL_0049 & hypothetical protein \\
\hline APL_0200 & hofQ & type II secretory pathway, component HofQ \\
\hline APL_0245 & APL_0245 & transferrin binding protein-like solute binding protein \\
\hline APL_0257 & APL_0257 & probable outer membrane protein \\
\hline APL_0276 & frpB & iron-regulated outer membrane protein B \\
\hline APL_0304 & palA & outer membrane protein precursor $\mathrm{PalA}$ \\
\hline APL_04I0 & APL_04IO & hypothetical outer membrane protein \\
\hline APL_04II & $D / \overline{5}$ & protective surface antigen DI5 precursor \\
\hline APL_0460 & $p l p D$ & lipoprotein Plp4 \\
\hline APL_0565 & cirA & hypothetical $A B C$ transporter ATP-binding protein \\
\hline APL_0649 & ompP2 & Outer membrane protein $\mathrm{P} 2$ precursor (OMP P2) \\
\hline APL_0829 & APL_0829 & hypothetical protein \\
\hline APL_0840 & APL_0840 & predicted outer membrane protein \\
\hline APL_0919 & $\operatorname{irp}$ & iron-regulated outer membrane protein \\
\hline APL_0959 & APL_0959 & hemagglutinin/hemolysin-like protein \\
\hline APL_0962 & ostA & organic solvent tolerance protein precursor \\
\hline APL_I42| & ompA & outer membrane protein P5 precursor \\
\hline APL_I567 & $\operatorname{tbpA}$ & transferrin-binding protein I Tbpl \\
\hline APL_I 1705 & APL_I 705 & FKBP-type peptidyl-prolyl cis-trans isomerase \\
\hline APL_I 1815 & $A P L_{-} / 815$ & hypothetical protein \\
\hline APL_I852 & ompA & Outer membrane protein P5 precursor (OMP P5) \\
\hline APL_1921 & pgaA & biofilm PGA synthesis protein PgaA precursor \\
\hline APL_2002 & APL_2002 & hypothetical protein \\
\hline
\end{tabular}

Predicted lipoproteins

\begin{tabular}{|c|c|}
\hline APL_0029 & APL_0029 \\
\hline APL_0036 & APL_0036 \\
\hline APL_0037 & slyB \\
\hline APL_0II6 & APL_0 $1 / 6$ \\
\hline APL_0I 24 & APL_0I 24 \\
\hline APL_0I56 & $a p b E$ \\
\hline APL_0227 & APL_0227 \\
\hline APL_0236 & APL_0236 \\
\hline APL_0332 & $h / p B$ \\
\hline APL_0356 & APL_0356 \\
\hline APL_0368 & potD2 \\
\hline APL_0378 & $g / p Q$ \\
\hline APL_0389 & ompP4 \\
\hline APL_0428 & smpA \\
\hline APL_0603 & APL_0603 \\
\hline APL_06I I & APL_06 I I \\
\hline APL_0642 & $m / t B$ \\
\hline APL_0777 & IolB \\
\hline APL_08I6 & mltA \\
\hline APL_0873 & $r l p B$ \\
\hline APL_0920 & APL_0920 \\
\hline APL_1062 & APL_I062 \\
\hline APL_II $\mid$ & $A P L \_I|2|$ \\
\hline APL_II52 & APL_I/52 \\
\hline APL_I 273 & APL_I 273 \\
\hline APL_I297 & APL_I 297 \\
\hline APL_1362 & APL_1362 \\
\hline APL_I404 & $o a p B$ \\
\hline
\end{tabular}

$A B C$ transporter periplasmic protein

hypothetical protein

outer membrane lipoprotein

hypothetical protein

hypothetical protein

thiamine biosynthesis lipoprotein ApbE precursor

hypothetical protein

putative lipoprotein

lipoprotein HlpB

hypothetical protein

spermidine/putrescine-binding periplasmic protein I precursor

glycerophosphoryl diester phosphodiesterase

lipoprotein E precursor

small protein A

hypothetical protein

putative lipoprotein

membrane-bound lytic murein transglycosylase B

outer-membrane lipoprotein LolB precursor

membrane-bound lytic murein transglycosylase $A$ precursor

putative rare lipoprotein B

hypothetical protein

hypothetical protein

putative lipoprotein

hypothetical protein

putative fimbrial biogenesis and twitching motility protein PilF-like protein

hypothetical protein

hypothetical protein

opacity associated protein B 
Table 2: In silico predicted OM proteins and lipoproteins from A. pleuropneumoniae (according to Chung et al. 2007), which are conserved amongst the $\mathbf{I}$ reference strains and the $2 \mathrm{I}$ field isolates tested by $\mathrm{M}-\mathrm{CGH}$ in this study. (Continued)

\begin{tabular}{lll}
\hline APL_I741 & mltC & Membrane-bound lytic murein transglycosylase C precursor \\
APL_1875 & APL_I875 & hypothetical protein \\
APL_1898 & APL_1898 & hypothetical protein \\
APL_1913 & pepO & neutral endopeptidase \\
APL_1930 & APL_1930 & Outer membrane antigenic lipoprotein B precursor \\
APL_1957 & APL_1957 & Lipoprotein_5 domain containing protein
\end{tabular}

defined as the signal intensity of A. pleuropneumoniae strain $5 \mathrm{~b}$ labeled with its appropriate fluorescent dye. The ratio of tester signal to control signal for each gene was transformed to its base 2 logarithm [89], $\log _{2}$ [Tester Signal/Control Signal], and is referred to as "Log2Ratio". Data from each channel were adjusted using cross-channel Loess normalization of the Log2Ratio data and low intensity and anomalous spots were flagged and removed. Data were stored and archived using the BASE BioArray Software Environment [90]. Microarray data from sets of hybridizations were exported from BASE after removal of flagged spots, Loess normalization, and averaging of data from duplicate spots on the microarray. At least three replicates of each strain were performed and the results averaged.

The microarrays for the A. pleuropneumoniae field strains were scanned with a Perkin-Elmer ScanArray Express scanner according to the manufacturer's recommendations. Image and data analysis were performed using TM4 suite of softwares from the J. Craig Venture Institute [91]. Raw data were generated using Spotfinder v.3.1.1. The integrated intensities of each spot, equivalent to the sum of unsaturated pixels in a spot were quantified and the integrated intensity of the local background was subtracted for each spot. The same operation was performed with the median spot intensities. Data were normalized with the MIDAS software tool using cross-channel Loess normalization. Spots with median intensities lower than 1000 were removed from the normalized data set. Intensities for duplicate spot were merged to generate the final normalized data set. The results were analyzed using the MEV software, first to check similarity of patterns of gene divergence within replicates for each serovar, then to examine data averaged across replicates of each serovar. Data were submitted to the Gene Expression Omnibus [GEO:GSE11921 and GSE14639].

To evaluate M-CGH results obtained using the different methods, we compared M-CGH data from A. pleuropneumoniae serovar1 versus serovar $5 \mathrm{~b}$ hybridizations that were collected, scanned and processed using ArrayPro software or SpotFinder/MIDAS software (Figure 6). Excellent correlation between M-CGH data was obtained using the two different data acquisition and analysis methods.

In cases where more than one reporter on the chip corresponded to a single gene, the data were averaged across the reporters. Visualization and hierarchical clustering of microarray data, using Euclidean Distance metrics and Average Linkage Clustering, was performed in MEV using algorithms developed by Eisen et al. [92]. To examine the variation of CGH profiles between the different serovar strains, we generated sample trees as well as support trees based on bootstrapping genes with 1000 iterations. Hierarchical clustering with Manhattan Distance metrics, as well as K-Median Clustering [53] (5 clusters, 1000 iterations) and Cluster Affinity Search Technique [54] (threshold $=0.55$ ) were also performed in MEV to ensure robustness of the clusters.

\section{Abbreviations}

AFLP: Amplified Fragment Length Polymorphism; BHI: Brain Heart Infusion; CPS: Capsular Polysaccharide; LPS: Lipopolysaccharide; M-CGH: Microarray-based Comparative Genomic Hybridization; MLEE: Multilocus Enzyme

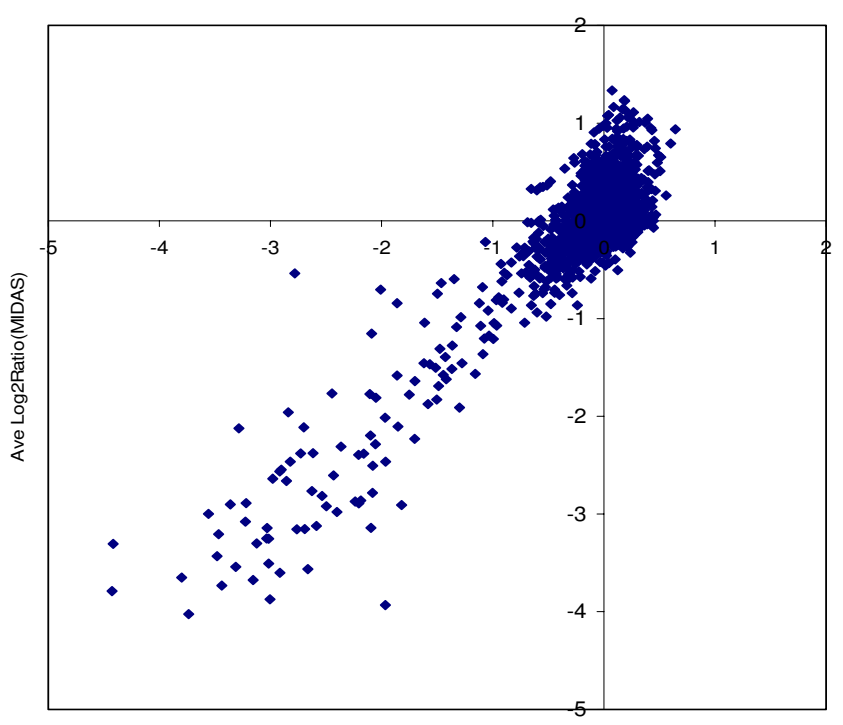

Ave Log2Ratio(ArrayPro)

\section{Figure 6}

Comparison between M-CGH Log2Ratio data from A. pleuropneumoniae serovar I versus serovar $5 \mathbf{b}$ hybridizations independently collected, scanned and processed using either ArrayPro software or SpotFinder/MIDAS software. At least 2 independent hybridizations were performed for each dataset, and the processed normalized data was averaged between replicate experiments and between pairs of duplicate spots on the microarray. 
Electrophoresis; NAD: Nicotinamide Adenosine Dinucleotide; OMP: Outer Membrane Protein; ORF: Open Reading Frame; PFGE: Pulsed-Field Gel Electrophoresis.

\section{Authors' contributions}

JG designed the M-CGH experiments and performed the hybridizations and data analysis with the field isolates. WAF managed the overall bioinformatics, analysed the microarray data from the 15 serovars, and contributed to the design and construction of the microarray. VD contributed to the design of the experiments and participated in the downstream analysis. $\mathrm{AB}$ performed the M-CGH hybridizations of the fifteen serovars strains and assisted with the construction of the microarray. SJF assisted with the design of the microarray and the bioinformatics analyses. JIM and JWC participated in the study design and revised the manuscript. JHEN and MJ participated in the conception and supervised the design of the study and revised the manuscript. All authors read and approved the final manuscript.

\section{Additional material}

\section{Additional file 1}

Mean Log2Ratio for genes that are divergent or highly divergent/ absent in at least one reference strain of A. pleuropneumoniae. A table listing all the genes that are either divergent or highly divergent/ absent in at least one of the 15 reference strains. The number of strains for which a particular gene is identified as divergent or highly divergent/ absent is also indicated.

Click here for file

[http://www.biomedcentral.com/content/supplementary/14712164-10-88-S1.doc]

\section{Acknowledgements}

We thank M. Ngeleka, D. Slavic and S. Messier for providing strains, the late Brian Agnew for his work in producing the DNA microarray, and K.R. Mittal for serotyping strains.

This work was supported by grants from the Natural Sciences and Engineering Research Council of Canada (Strategic grant 306730-04 to JWC and MJ) and by the National Research Council of Canada Genomics and Health Research Program (Phase II) to JHEN. VD is a recipient of a FQRNT scholarship and JG of a Michel-Saucier postdoctoral fellowship.

\section{References}

I. Torremorell M, Pijoan C, Janni K, Walker R, Joo HS: Airborne transmission of Actinobacillus pleuropneumoniae and porcine reproductive and respiratory syndrome virus in nursery pigs. Am J Vet Res 1997, 58(8):828-832.

2. Jobert JL, Savoye C, Cariolet R, Kobisch M, Madec F: Experimental aerosol transmission of Actinobacillus pleuropneumoniae to pigs. Can J Vet Res 2000, 64(I):2I-26.

3. Lechtenberg KF, Shryock TR, Moore G: Characterization of an Actinobacillus pleuropneumoniae seeder pig challenge-exposure model. Am J Vet Res 1994, 55( I 2): 1703-1709.

4. Taylor DJ: Actinobacillus pleuropneumoniae. In Diseases of Swine 8th edition. Edited by: Straw BE. Ames: lowa State University Press; 1999.
5. Nicolet J: Actinobacillus pleuropneumoniae. In Diseases of Swine 7th edition. Edited by: Leman AD. Ames: lowa State University Press; 1992.

6. Dubreuil JD, Jacques M, Mittal KR, Gottschalk M: Actinobacillus pleuropneumoniae surface polysaccharides: their role in diagnosis and immunogenicity. Anim Health Res Rev 2000, I (2):73-93.

7. Perry MB: Structural analysis of the lipopolysaccharide of Actinobacillus (Haemophilus) pleuropneumoniae serotype 10. Biochem Cell Biol 1990, 68(4):808-8I0.

8. Mittal KR, Higgins R, Lariviere $S$ : Identification and serotyping of Haemophilus pleuropneumoniae by coagglutination test. J Clin Microbiol | 983, | 8(6): | 35|-| 354.

9. Kamp EM, Vermeulen TM, Smits MA, Haagsma J: Production of Apx toxins by field strains of Actinobacillus pleuropneumoniae and Actinobacillus suis. Infect Immun 1994, 62(9):4063-4065.

10. Nielsen R, Andresen LO, Plambeck T, Nielsen JP, Krarup LT, Jorsal SE: Serological characterization of Actinobacillus pleuropneumoniae biotype 2 strains isolated from pigs in two Danish herds. Vet Microbiol I997, 54(I):35-46.

II. Mittal KR: Cross-reactions between Actinobacillus (Haemophilus) pleuropneumoniae strains of serotypes I and 9. J Clin Microbiol 1990, 28(3):535-539.

12. Mittal KR, Higgins R, Lariviere S: Serologic studies of Actinobacillus (Haemophilus) pleuropneumoniae strains of serotype-3 and their antigenic relationships with other $A$ pleuropneumoniae serotypes in swine. Am J Vet Res 1988, 49(2): I52-155.

13. Mittal KR, Bourdon S: Cross-reactivity and antigenic heterogeneity among Actinobacillus pleuropneumoniae strains of serotypes 4 and 7. J Clin Microbiol I99I, 29(7): I344-1347.

14. Blackall PJ, Bowles R, Pahoff JL, Smith BN: Serological characterisation of Actinobacillus pleuropneumoniae isolated from pigs in 1993 to 1996. Aust Vet J 1999, 77(1):39-43.

15. Blackall PJ, Klaasen HL, Bosch $\mathrm{H}$ van den, Kuhnert P, Frey J: Proposal of a new serovar of Actinobacillus pleuropneumoniae: serovar 15. Vet Microbiol 2002, 84(I-2):47-52

16. Jacques M: Surface polysaccharides and iron-uptake systems of Actinobacillus pleuropneumoniae. Can J Vet Res 2004, 68(2):8I-85.

17. Bosse JT, Janson H, Sheehan BJ, Beddek AJ, Rycroft AN, Kroll JS, Langford PR: Actinobacillus pleuropneumoniae: pathobiology and pathogenesis of infection. Microbes Infect 2002, 4(2):225-235.

18. Haesebrouck F, Chiers K, Van Overbeke I, Ducatelle R: Actinobacillus pleuropneumoniae infections in pigs: the role of virulence factors in pathogenesis and protection. Vet Microbiol 1997, 58(2-4):239-249.

19. Jacques M, Foiry B, Higgins R, Mittal KR: Electron microscopic examination of capsular material from various serotypes of Actinobacillus pleuropneumoniae. I Bacteriol 1988 I70(7):3314-3318.

20. Frey ]: Virulence in Actinobacillus pleuropneumoniae and RTX toxins. Trends Microbiol I995, 3(7):257-26I.

2I. Rosendal S, Maclnnes Jl: Characterization of an attenuated strain of Actinobacillus pleuropneumoniae, serotype I. Am J Vet Res 1990, 5 I(5):7II-7I7.

22. Ramjeet M, Deslandes V, Goure J, Jacques M: Actinobacillus pleuropneumoniae vaccines: from bacterins to new insights into vaccination strategies. Anim Health Res Rev 2008, 9(I):25-45.

23. Chiers K, van Overbeke I, De Laender P, Ducatelle R, Carel S, Haesebrouck F: Effects of endobronchial challenge with Actinobacillus pleuropneumoniae serotype 9 of pigs vaccinated with inactivated vaccines containing the Apx toxins. Vet $Q 1998$, 20(2):65-69.

24. Rossi-Campos A, Anderson C, Gerlach GF, Klashinsky S, Potter AA, Willson PJ: Immunization of pigs against Actinobacillus pleuropneumoniae with two recombinant protein preparations. Vaccine 1992, I0(8):5।2-518.

25. Haesebrouck F, Pasmans F, Chiers K, Maes D, Ducatelle R, Decostere A: Efficacy of vaccines against bacterial diseases in swine: what can we expect? Vet Microbiol 2004, $100(3-4): 255-268$.

26. Van Overbeke I, Chiers K, Ducatelle R, Haesebrouck F: Effect of endobronchial challenge with Actinobacillus pleuropneumoniae serotype 9 of pigs vaccinated with a vaccine containing Apx toxins and transferrin-binding proteins. J Vet Med $B$ Infect Dis Vet Public Health 200I, 48(I):I5-20.

27. Moller K, Nielsen R, Andersen LV, Kilian M: Clonal analysis of the Actinobacillus pleuropneumoniae population in a geographi- 
cally restricted area by multilocus enzyme electrophoresis. J Clin Microbiol 1992, 30(3):623-627.

28. Musser JM, Rapp VJ, Selander RK: Clonal diversity in Haemophilus pleuropneumoniae. Infect Immun I987, 55(5): I207-I2I5.

29. Chevallier B, Dugourd D, Tarasiuk K, Harel J, Gottschalk M, Kobisch $M$, Frey J: Chromosome sizes and phylogenetic relationships between serotypes of Actinobacillus pleuropneumoniae. FEMS Microbiol Lett 1998, 160(2):209-216.

30. Kokotovic B, Angen O: Genetic diversity of Actinobacillus pleuropneumoniae assessed by amplified fragment length polymorphism analysis. J Clin Microbiol 2007, 45( I 2):392I-3929.

31. Maclnnes JI, Borr JD, Massoudi M, Rosendal S: Analysis of southern Ontario Actinobacillus (Haemophilus) pleuropneumoniae isolates by restriction endonuclease fingerprinting. Can J Vet Res 1990, 54(2):244-250.

32. Borr JD, Ryan DA, Maclnnes Jl: Analysis of Actinobacillus pleuropneumoniae and related organisms by DNA-DNA hybridization and restriction endonuclease fingerprinting. Int J Syst Bacteriol I99|, 4 I (I): I II-I29.

33. Foote SJ, Bosse JT, Bouevitch AB, Langford PR, Young NM, Nash JH: The complete genome sequence of Actinobacillus pleuropneumoniae L20 (serotype 5b). J Bacteriol 2008, 190(4): | 495-| 496.

34. Chung JW, Ng-Thow-Hing C, Budman LI, Gibbs BF, Nash JH, Jacques M, Coulton JW: Outer membrane proteome of Actinobacillus pleuropneumoniae: LC-MS/MS analyses validate in silico predictions. Proteomics 2007, 7(II): 1854-1865.

35. Xu Z, Zhou Y, Li L, Zhou R, Xiao S, Wan Y, Zhang S, Wang K, Li W, Jin $\mathrm{H}$, et al:: Genome biology of Actinobacillus pleuropneumoniae JL03, an isolate of serotype 3 prevalent in China. PLOS ONE 2008, 3(I): el 450.

36. Leonard EE 2nd, Takata T, Blaser MJ, Falkow S, Tompkins LS, Gaynor EC: Use of an open-reading frame-specific Campylobacter jejuni DNA microarray as a new genotyping tool for studying epidemiologically related isolates. J Infect Dis 2003, 187(4):69|-694.

37. Taboada EN, Acedillo RR, Luebbert CC, Findlay WA, Nash JH: A new approach for the analysis of bacterial microarray-based Comparative Genomic Hybridization: insights from an empirical study. BMC Genomics 2005, 6(I):78.

38. Nash JH, Findlay WA, Luebbert CC, Mykytczuk OL, Foote SJ, Taboada EN, Carrillo CD, Boyd JM, Colquhoun DJ, Reith ME, et al: Comparative genomics profiling of clinical isolates of Aeromonas salmonicida using DNA microarrays. BMC Genomics 2006 7:43.

39. Pearson BM, Pin C, Wright J, I'Anson K, Humphrey T, Wells JM: Comparative genome analysis of Campylobacter jejuni using whole genome DNA microarrays. FEBS Lett 2003, 554(I2):224-230.

40. Dorrell N, Mangan JA, Laing KG, Hinds J, Linton D, Al-Ghusein H, Barrell BG, Parkhill J, Stoker NG, Karlyshev AV, et al:: Whole genome comparison of Campylobacter jejuni human isolates using a low-cost microarray reveals extensive genetic diversity. Genome Res 200I, I I(I 0): 1706-I7I5.

4I. Tsolaki AG, Hirsh AE, DeRiemer K, Enciso JA, Wong MZ, Hannan M, Goguet de la Salmoniere YO, Aman K, Kato-Maeda M, Small PM: Functional and evolutionary genomics of Mycobacterium tuberculosis: insights from genomic deletions in 100 strains. Proc Natl Acad Sci USA 2004, I 0 I( I 4):4865-4870.

42. Salama N, Guillemin K, McDaniel TK, Sherlock G, Tompkins L, Falkow S: A whole-genome microarray reveals genetic diversity among Helicobacter pylori strains. Proc Natl Acad Sci USA 2000, 97(26): | 14668-| 4673.

43. Deslandes V, Nash JH, Harel J, Coulton JW, Jacques M: Transcriptional profiling of Actinobacillus pleuropneumoniae under iron-restricted conditions. BMC Genomics 2007, 8:72.

44. Perry MB, Altman E, Brisson J-R, Beynon LM, Richards JC: Structural characteristics of the antigenic capsular polysaccharides and lipopolysaccharides involved in the serological classification of Actinobacillus (Haemophilus) pleuropneumoniae. Serodiagnosis and Immunotherapy of Infectious Diseases 1990, 4:299-308.

45. Altman E, Brisson JR, Gagne SM, Perry MB: Structure of the capsular polysaccharide of Actinobacillus pleuropneumoniae serotype 5b. Eur J Biochem 1992, 204(I):225-230.
46. Altman E, Brisson JR, Perry MB: Structure of the capsular polysaccharide of Haemophilus pleuropneumoniae serotype 5 . Eur J Biochem 1987, I 70(I-2): 185-192.

47. Altman E, Griffith DW, Perry MB: Structural studies of the $\mathbf{O}$ chains of the lipopolysaccharides produced by strains of Actinobacillus (Haemophilus) pleuropneumoniae serotype 5. Biochem Cell Biol 1990, 68( I I): I 268-I27I.

48. Beck M, Bosch JF van den, Jongenelen IM, Loeffen PL, Nielsen R, Nicolet J, Frey J: RTX toxin genotypes and phenotypes in Actinobacillus pleuropneumoniae field strains. J Clin Microbiol 1994, 32(I I):2749-2754.

49. Schaller A, Kuhn R, Kuhnert P, Nicolet J, Anderson TJ, Maclnnes II, Segers RP, Frey J: Characterization of apxIVA, a new RTX determinant of Actinobacillus pleuropneumoniae. Microbiology 1999, I45(Pt 8):2105-2116.

50. Frey J, Kuhnert P: RTX toxins in Pasteurellaceae. Int J Med Microbiol 2002, 292(3-4): 149-158.

51. Cho WS, Chae C: Genotypic prevalence of apxIV in Actinobacillus pleuropneumoniae field isolates. J Vet Diagn Invest 200I, I3(2): I75-177.

52. Koyama T, To H, Nagai S: Isolation of Actinobacillus pleuropneumoniae serovar 15-like strain from a field case of porcine pleuropneumonia in Japan. J Vet Med Sci 2007, 69(9):961-964.

53. Soukas A, Cohen P, Socci ND, Friedman JM: Leptin-specific patterns of gene expression in white adipose tissue. Genes Dev 2000, 14(8):963-980.

54. Ben-Dor A, Shamir R, Yakhini Z: Clustering gene expression patterns. J Comput Biol I999, 6(3-4):28I-297.

55. Higgins R, Lariviere S, Mittal KR, Martineau GP, Rousseau P, Cameron $\mathrm{J}$ : Evaluation of a killed vaccine against porcine pleuropneumonia Due to Haemophilus pleuropneumoniae. Can Vet J 1985 26(2):86-89.

56. Fenwick B, Henry S: Porcine pleuropneumonia. J Am Vet Med Assoc 1994, 204(9): I334-1340.

57. Thacker BJ, Mulks MH: Evaluation of commercial Haemophilus pleuropneumoniae vaccines. Proc Int Pig Vet Soc 1988, I0(87):

58. Baltes N, Gerlach GF: Identification of genes transcribed by Actinobacillus pleuropneumoniae in necrotic porcine lung tissue by using selective capture of transcribed sequences. Infect Immun 2004, 72(I I):67| I-67। I6.

59. Sheehan BJ, Bosse JT, Beddek AJ, Rycroft AN, Kroll JS, Langford PR: Identification of Actinobacillus pleuropneumoniae genes important for survival during infection in its natural host. Infect Immun 2003, 7 I (7):3960-3970.

60. Fuller TE, Martin S, Teel JF, Alaniz GR, Kennedy MJ, Lowery DE: Identification of Actinobacillus pleuropneumoniae virulence genes using signature-tagged mutagenesis in a swine infection model. Microb Pathog 2000, 29(I):39-5I.

61. Willson PJ, Gerlach GF, Klashinsky S, Potter AA: Cloning and characterization of the gene coding for NADPH-sulfite reductase hemoprotein from Actinobacillus pleuropneumoniae and use of the protein product as a vaccine. Can J Vet Res 200I, 65(4):206-2I2.

62. Mahasreshti PJ, Murphy GL, Wyckoff JH 3rd, Farmer S, Hancock RE, Confer AW: Purification and partial characterization of the OmpA family of proteins of Pasteurella haemolytica. Infect Immun 1997, 65(I):21 I-2I8

63. Zeng H, Pandher K, Murphy GL: Molecular cloning of the Pasteurella haemolytica pomA gene and identification of bovine antibodies against PomA surface domains. Infect Immun 1999, 67(9):4968-4973.

64. Oldfield NJ, Donovan EA, Worrall KE, Wooldridge KG, Langford PR, Rycroft AN, Ala'Aldeen DA: Identification and characterization of novel antigenic vaccine candidates of Actinobacillus pleuropneumoniae. Vaccine 2008, 26(16): 1942-1954.

65. Bosch $\mathrm{H}$ van den, Frey J: Interference of outer membrane protein PalA with protective immunity against Actinobacillus pleuropneumoniae infections in vaccinated pigs. Vaccine 2003 , 2I (25-26):360I-3607

66. Nardini PM, Mellors A, Lo RY: Characterization of a fourth lipoprotein from Pasteurella haemolytica AI and its homology to the OmpA family of outer membrane proteins. FEMS Microbiol Lett 1998, 165(I):71-77.

67. Fan $X$, Goldfine $H$, Lysenko $E$, Weiser JN: The transfer of choline from the host to the bacterial cell surface requires glpQ in Haemophilus influenzae. Mol Microbiol 200I, 4I(5): 1029-1036. 
68. Akkoyunlu M, Janson H, Ruan M, Forsgren A: Biological activity of serum antibodies to a nonacylated form of lipoprotein $D$ of Haemophilus influenzae. Infect Immun I996, 64(I I ):4586-4592.

69. Lo M, Boyce JD, Wilkie IW, Adler B: Characterization of two lipoproteins in Pasteurella multocida. Microbes Infect 2004, 6(I):58-67.

70. Murphy TF, Campagnari AA, Nelson MB, Apicella MA: Somatic antigens of Haemophilus influenzae as vaccine components. Pediatr Infect Dis J 1989, 8(I Suppl):S66-68.

7I. Reilly TJ, Smith AL: Purification and characterization of a recombinant Haemophilus influenzae outer membrane phosphomonoesterase e (P4). Protein Expr Purif 1999, I 7(3):401 -409.

72. Reilly TJ, Chance DL, Smith AL: Outer membrane lipoprotein e (P4) of Haemophilus influenzae is a novel phosphomonoesterase. J Bacteriol 1999, I 8 I (2 I):6797-6805

73. Kemmer G, Reilly TJ, Schmidt-Brauns J, Zlotnik GW, Green BA, Fiske MJ, Herbert M, Kraiss A, Schlor S, Smith A, et al.: NadN and e (P4) are essential for utilization of NAD and nicotinamide mononucleotide but not nicotinamide riboside in Haemophilus influenzae. J Bacteriol 200I, I 83( I 3):3974-398I.

74. Hotomi M, Ikeda Y, Suzumoto M, Yamauchi K, Green BA, Zlotnick G, Billal DS, Shimada J, Fujihara K, Yamanaka N: A recombinant P4 protein of Haemophilus influenzae induces specific immune responses biologically active against nasopharyngeal colonization in mice after intranasal immunization. Vaccine 2005 23(10): 1294-1300.

75. Deich RA, Anilionis A, Fulginiti J, Metcalf BJ, Quataert S, Quinn-Dey T, Zlotnick GW, Green BA: Antigenic conservation of the I 5,000-dalton outer membrane lipoprotein PCP of Haemophilus influenzae and biologic activity of anti-PCP antisera. Infect Immun 1990, 58( I 0):3388-3393.

76. Pandher K, Murphy GL: Genetic and immunological analyses of a 38 kDa surface-exposed lipoprotein of Pasteurella haemoIytica Al. Vet Microbiol 1996, 5 I(3-4):33 I-34I.

77. Polissi A, Pontiggia A, Feger G, Altieri M, Mottl H, Ferrari L, Simon D: Large-scale identification of virulence genes from Streptococcus pneumoniae. Infect Immun 1998, 66( I 2):5620-5629.

78. Ware D, Watt J, Swiatlo E: Utilization of putrescine by Streptococcus pneumoniae during growth in choline-limited medium. J Microbiol 2005, 43(5):398-405.

79. Shah $\mathrm{P}$, Swiatlo E: Immunization with polyamine transport protein PotD protects mice against systemic infection with Streptococcus pneumoniae. Infect Immun 2006 74(10):5888-5892.

80. Thomas KL, Leduc I, Olsen B, Thomas CE, Cameron DW, Elkins C: Cloning, overexpression, purification, and immunobiology of an 85-kilodalton outer membrane protein from Haemophilus ducreyi. Infect Immun 200I, 69(7):4438-4446.

8I. Manning DS, Reschke DK, Judd RC: Omp85 proteins of Neisseria gonorrhoeae and Neisseria meningitidis are similar to Haemophilus influenzae D-I5-Ag and Pasteurella multocida Oma87. Microb Pathog 1998, 25(I): I I-2I.

82. Flack FS, Loosmore $S$, Chong $P$, Thomas WR: The sequencing of the $80-k D a$ DI5 protective surface antigen of Haemophilus influenzae. Gene 1995, I56(I):97-99.

83. Ruffolo CG, Adler B: Cloning, sequencing, expression, and protective capacity of the oma87 gene encoding the Pasteurella multocida 87-kilodalton outer membrane antigen. Infect Immun 1996, 64(8):3161-3167.

84. Thomas WR, Callow MG, Dilworth RJ, Audesho AA: Expression in Escherichia coli of a high-molecular-weight protective surface antigen found in nontypeable and type b Haemophilus influenzae. Infect Immun 1990, 58(6): 1909-1913.

85. Yang Y, Thomas WR, Chong P, Loosmore SM, Klein MH: A 20-kilodalton $\mathbf{N}$-terminal fragment of the DI5 protein contains a protective epitope(s) against Haemophilus influenzae type a and type b. Infect Immun 1998, 66(7):3349-3354.

86. Loosmore SM, Yang YP, Coleman DC, Shortreed JM, England DM, Klein MH: Outer membrane protein DI5 is conserved among Haemophilus influenzae species and may represent a universal protective antigen against invasive disease. Infect Immun 1997, 65(9):3701-3707.

87. Rozen S, Skaletsky H: Primer3 on the WWW for general users and for biologist programmers. Methods Mol Biol 2000, 132:365-386.
88. Taboada EN, Acedillo RR, Carrillo CD, Findlay WA, Medeiros DT, Mykytczuk OL, Roberts MJ, Valencia CA, Farber JM, Nash JH: Largescale comparative genomics meta-analysis of Campylobacter jejuni isolates reveals low level of genome plasticity. J Clin Microbiol 2004, 42( I 0):4566-4576.

89. Smyth GK, Yang YH, Speed T: Statistical issues in cDNA microarray data analysis. Methods $\mathrm{Mol} \mathrm{Biol} 2003,224:$ I I I-I 36.

90. Saal LH, Troein C, Vallon-Christersson J, Gruvberger S, Borg A, Peterson C: BioArray Software Environment (BASE): a platform for comprehensive management and analysis of microarray data. Genome Biol 2002, 3(8):SOFTWARE0003.

91. Saeed Al, Sharov V, White J, Li J, Liang W, Bhagabati N, Braisted J, Klapa M, Currier T, Thiagarajan M, et al.: TM4: a free, open-source system for microarray data management and analysis. Biotechniques 2003, 34(2):374-378.

92. Eisen MB, Spellman PT, Brown PO, Botstein D: Cluster analysis and display of genome-wide expression patterns. Proc Nat Acad Sci USA 1998, 95(25): |4863-|4868.
Publish with Biomed Central and every scientist can read your work free of charge

"BioMed Central will be the most significant development for disseminating the results of biomedical research in our lifetime. "

Sir Paul Nurse, Cancer Research UK

Your research papers will be:

- available free of charge to the entire biomedical community

- peer reviewed and published immediately upon acceptance

- cited in PubMed and archived on PubMed Central

- yours - you keep the copyright
BioMedcentral 